\title{
Silver nanoparticles induce genetic, biochemical, and phenotype variation in chrysanthemum
}

\author{
Alicja Tymoszuk $^{1}$ (D) Dariusz Kulus $^{1}$ (i)
}

Received: 21 May 2020 / Accepted: 19 August 2020 / Published online: 27 August 2020

(c) The Author(s) 2020

\begin{abstract}
Despite the tremendous progress in breeding, novel and user-friendly techniques of plant improvement are desirable. The study aimed to analyze the usefulness of silver nanoparticles (AgNPs) in the breeding of chrysanthemum: one of the top ornamental plant species. In vitro regeneration of adventitious shoots from internodes of chrysanthemum 'Lilac Wonder' was induced on the modified Murashige and Skoog (MS) medium supplemented with $0.6 \mathrm{mg} \mathrm{L}^{-1}$ 6-benzylaminopurine (BAP), $2 \mathrm{mg} \mathrm{L}^{-1}$ indole-3-acetic acid (IAA) and AgNPs at 0, 5, 10 and $20 \mathrm{ppm}$ concentration. The efficiency of callogenesis and caulogenesis were analyzed after 10 weeks of culture. The concentration of chlorophylls, carotenoids, and phenolic compounds in shoots and calli were estimated. Plants obtained from 20 ppm AgNPs treatment were additionally analyzed on the genetic level using randomly amplified polymorphic DNA (RAPD) and inter simple sequence repeats (ISSR) markers. In vitro rooted shoots were acclimatized in the glasshouse and subjected to biochemical and phenotype stability evaluation. AgNPs at the highest concentration (20 ppm) suppressed both callogenesis and caulogenesis in vitro. The concentration of metabolites in callus was stable, regardless of AgNPs treatment, except for carotenoids which production was enhanced by 20 ppm AgNPs. In contrast, the content of chlorophyll $a$ and $b$ in shoots varied depending on AgNPs treatment. Polymorphic loci were detected in 12 and 9 AgNPs-treated-plants by RAPD and ISSR markers, respectively (one of which was common to both marker systems). Rooting and acclimatization were fully successful in all experimental combinations. Phenotype alternations were detected in six plants; one from 10 ppm AgNPs treatment and five from 20 ppm treatment. They included variation in pigment content (anthocyanins and carotenoids) and/or inflorescence shape. Interestingly, only two plants revealed both genetic and phenotype polymorphisms. No genetic or phenotype variation was detected in the control plants. In conclusion, AgNPs can be used in chrysanthemum breeding.
\end{abstract}

\section{Key message}

Silver nanoparticles added to the culture medium affect the regeneration and metabolism of plants. Moreover, they may be a source of significant genetic and phenotype variation in the in vitro-propagated chrysanthemum.

Keywords Chrysanthemum $\times$ grandiflorum $\cdot$ ISSR $\cdot$ Metabolites $\cdot$ Mutagenesis $\cdot$ Nanotechnology $\cdot$ RAPD

\section{Introduction}

Chrysanthemum $\times$ grandiflorum /Ramat./Kitam. is one of the most valuable and popular ornamental plant species in the horticultural market. It is produced for cut flowers, in pots, undercover and in the ground. Chrysanthemum occupies the second place on the world sales list, following the rose (Miler and Jędrzejczyk 2018). This popularity is due to various-shaped and multi-colored inflorescences, long flowering period, habit diversity, as well as broad use in horticulture and medicine (Mukherjee et al. 2013). Despite
Alicja Tymoszuk

alicja.tymoszuk@utp.edu.pl

1 Laboratory of Ornamental Plants and Vegetable Crops, Faculty of Agriculture and Biotechnology, UTP University of Science and Technology in Bydgoszcz, 6 Bernardyńska Str., 85-029 Bydgoszcz, Poland 
the great number of cultivars available, customers and breeders are constantly searching for new phenotypes.

The most commonly applied breeding methods with chrysanthemum include generative crossing (hybridization), mutation breeding and somaclonal variation induction, as well as genetic transformation (Teixeira da Silva and Kulus 2014). Chrysanthemum is a species with a quite high frequency of induced and spontaneous mutation occurrence, especially the pink/purple flowering cultivars. Similarly to other plant species, mutations in chrysanthemum are usually recessive, i.e. the dominant allele changes to the recessive type, which makes the effect easily identified on the phenotype level when in homozygous combination (Nanjundiah 1993). Typically, the variation is visible as the change in color, shape, or size of inflorescence, already in the first mutant generation (Zalewska et al. 2010, 2011). Due to the development of in vitro technologies, mutants can be easily propagated, even chimeras composed of cells with more than one distinct genotype (Tymoszuk et al. 2014). Tissue culture has tremendous potential in breeding, which is still not fully exploited. The addition of metal nano-colloids into the culture medium can become a cheap, easy, and effective way not only to stimulate the explant regeneration (Tymoszuk and Miler 2019), but also to induce genetic variation.

Nanoparticles (NPs) are defined as atomic or molecular aggregates of size less than $100 \mathrm{~nm}$ in at least one dimension and characterized by unique physicochemical properties, i.e. high surface to volume ratio, high reactivity, and easy absorption by cells (Fayez et al. 2017; Singh et al. 2018). Carbon nanotubes, aluminum, copper, gold, iron, silver, silica, zinc, zinc oxide, and titanium dioxide nanoparticles are among the most commonly manufactured NPs worldwide (Khot et al. 2012; Sabir et al. 2014; Cvjetko et al. 2018). They are used in numerous disciplines, e.g. optics, electronics, energetics, material sciences, medicine, and life sciences (Reed et al. 2012; Faizan et al. 2018; Hou et al. 2018).

Despite the increasing application of nanotechnology in agriculture, the genotoxic effects of NPs have been poorly studied in plants, while the majority of research focused on mammalian and bacteria organisms (Mehrian and De Lima 2016). Therefore, studies with plant materials are also needed. Nanoparticles induce genotoxicity either directly or indirectly. In the direct mechanism, NPs are passing through the cell and nucleus membrane and interact with the DNA mechanically or by chemical binding. Indirect genotoxicity of NPs results from interaction with the nuclear proteins (involved in replication, transcription, translations, etc.) or induced oxidative stress (Mehrian and De Lima 2016). Various chromosomal abnormalities, such as chromatin bridge, stickiness, disturbed metaphase, and chromosomal breaks affecting the mitosis were reported in Vicia faba root-tips exposed to AgNPs (Patllola et al. 2012), Allium cepa root-tip meristems exposed to zinc oxide nanoparticles (ZnONPs)
(Kumari et al. 2011), A. cepa root-tip cells exposed to AgNPs (Panda et al. 2011), and other NPs-treated crops (Ghosh et al. 2019). Consequently, nanoparticles may affect the development, metabolism, and phenotype of plants. Interestingly, the impact of nanoparticles on plant growth and development strongly depends on the chemical composition of NPs, their size, shape, surface area, surface coatings, concentration, type of synthesis (chemical or biosynthesis), solvent applied, as well as the plant itself; its genotype, age, developmental stage, or chemical milieu of the cell (Barrena et al. 2009; Dietz and Herth 2011; Syu et al. 2014; Vannini et al. 2014; Barbasz et al. 2018). An increase in shoot and root length, leaf surface, and protein content in common bean (Phaseolus vulgaris L.) and corn (Zea mays L.) were reported after treating the in vivo-grown plants with low concentrations of AgNPs (20-60 ppm). Higher concentrations inhibited the growth of plants (Salama 2012). Silver nanoparticles applicated at the concentration of $10 \mathrm{ppm}$ inhibited the regeneration of adventitious roots in vitro in chrysanthemum and gerbera (Gerbera $\times$ jamesonii $\mathrm{H}$. Bol.), but, at the same time, improved the efficiency of Cape Primrose (Streptocarpus $\times$ hybridus Voss) micropropagation (Tymoszuk and Miler 2019). On the other hand, there are no studies on the mutagenic properties of AgNPs inducing somaclonal variation in in vitro propagated plants.

The aim of this study was to verify, for the first time, the genetic, biochemical, and phenotype stability of chrysanthemum 'Lilac Wonder' treated in vitro with AgNPs at the concentration of 5, 10 or $20 \mathrm{ppm}$. The 'Lilac Wonder' cultivar is characterized by pink, full semi-ball inflorescence and was previously successfully used in breeding programs, which confirmed its genetic uniformity; i.e. non-chimeric structure (Zalewska et al. 2010).

\section{Materials and methods}

\section{Regeneration medium and general growing conditions in vitro}

In the experiment, the Murashige and Skoog (MS) basal medium was used (Murashige and Skoog 1962), modified with the increased by half content of calcium and iron $\left(660 \mathrm{mg} \mathrm{L}^{-1} \mathrm{CaCl}_{2} \cdot 2 \mathrm{H}_{2} \mathrm{O}, 41.7 \mathrm{mg} \mathrm{L}{ }^{-1} \mathrm{FeSO}_{4} \cdot 7 \mathrm{H}_{2} \mathrm{O}\right.$, and $55.8 \mathrm{mg} \mathrm{L}^{-1} \mathrm{Na}_{2}$ EDTA.2 $\mathrm{H}_{2} \mathrm{O}$ ) (Chemia, Bydgoszcz, Poland). The medium was supplemented with plant growth regulators (PGRs): $0.6 \mathrm{mg} \mathrm{L}^{-1}$ 6-benzylaminopurine (BAP) and $2 \mathrm{mg} \mathrm{L}^{-1}$ indole-3-acetic acid (IAA) (Sigma-Aldrich, St. Louis, MO, USA) to stimulate the regeneration of adventitious shoots. Silver nanoparticles (AgNPs) were added into the medium at the concentration of 5,10 or $20 \mathrm{ppm}(0.005$; $0.01 ; 0.02 \mathrm{mg} \mathrm{mL}^{-1}$, respectively). The medium contained $30 \mathrm{~g} \mathrm{~L}^{-1}$ sucrose and was solidified with $0.8 \%$ (w/v) Plant 
Propagation LAB-AGAR ${ }^{\mathrm{TM}}$ (BIOCORP, Warsaw, Poland) having added all the nutrients, before autoclaving at $121^{\circ} \mathrm{C}$ for $20 \mathrm{~min}$. The medium $\mathrm{pH}$ was set to 5.8. Tissue cultures were kept in 350-mL glass jars sealed with plastic caps, poured with $40 \mathrm{~mL}$ of the medium.

In vitro cultures were kept in the growth room at the temperature of $23 \pm 1{ }^{\circ} \mathrm{C}$, exposed to a $16 / 8$-h day/night regime, using Philips TLD 36 W/54 fluorescent lamps emitting cool daylight (Koninklijke Philips Electronics N.V., Eindhoven, the Netherlands), at approximately $35 \mu \mathrm{mol} \mathrm{m}^{-2} \mathrm{~s}^{-1}$ photosynthetic photon flux density.

\section{Detailed characteristics of nanoparticles}

Silver nanoparticles (AgNPs) were purchased from Nanoparticles Innovation NPIN s.c. (Łódź, Poland). According to the manufacturer information, AgNPs were produced by the seeded-mediated growth method described elsewhere (Domeradzka-Gajda et al. 2017; Pudlarz et al. 2018). The synthesis was set to obtain the final concentration of nanometal at $100 \mathrm{ppm}$. The hydrodynamic size of AgNPs in colloids was $23 \pm 4 \mathrm{~nm}$, confirmed by Dynamic Light Scattering (DLS; Nano ZS Zetasizer system, Malvern Instruments, Malvern, UK). The size and size distribution were measured by Scanning Transmission Electron Microscopy (STEM) (Nova NanoSEM 450, FEI ${ }^{\mathrm{TM}}$, Hillsboro, OR, USA), at accelerating voltage $30 \mathrm{kV}$, and reached $20 \pm 3 \mathrm{~nm}$ (Fig. 1).

\section{Plant material and adventitious organogenesis}

Chrysanthemum $\times$ grandiflorum /Ramat./Kitam. 'Lilac Wonder' internodes, dissected from plantlets multiplied previously in vitro with the single-node method on the modified MS medium without PGRs or AgNPs (MS0), were used as explants and inoculated horizontally on the regeneration medium. Five internodes were placed per jar, 10 jars were used in each experimental object. Two jars were considered a single repetition; i.e. five repetitions were included. Internodes inoculated on the regeneration medium without the addition of AgNPs (0 ppm) were used as the control. For nine successive weeks, the dynamics of shoots regeneration was observed. In the 10th week of culture, the share of explants forming calli, share of explants forming shoots, and the mean number of shoots per inoculated explant were estimated.

Regenerated adventitious shoots (not hyperhydrated and longer than $2 \mathrm{~cm}$ ), 85-100 from each experimental combination, were transferred onto the modified MS rooting medium supplemented with $2.0 \mathrm{mg} \mathrm{L}^{-1}$ IAA for 2 weeks. Additionally, a genotype/phenotype standard of 'Lilac Wonder' consisting of 25 shoots multiplied previously in vitro via the single-node method on the modified MS0 medium was included for genetic analyses and ex vitro cultivation.

\section{Genetic stability evaluation}

The genetic fidelity of 20 ppm AgNPs-treated plants, after 10 weeks of in vitro culture, was assessed using randomly amplified polymorphic DNA (RAPD) and inter simple sequence repeats (ISSR). A total of 85 adventitious shoots produced from AgNPs-treated explants and 25 untreated in vitro-grown standard plants were included in the analysis.

Total genomic DNA was isolated from fresh tissues using a Genomic Mini AX Plant SPIN Kit (A\&A Biotechnology, Gdynia, Poland), according to the manufacturer's instruction. The concentration of DNA was measured and standardized with a NanoDrop 1000 spectrophotometer (Thermo Fisher Scientific, Waltham, MA, USA). The isolated DNA was stored at $4{ }^{\circ} \mathrm{C}$.

A total of 10 primers (5 RAPD and 5 ISSR) were used for the PCR reaction. PCR was performed in a BioRad C1000 Touch thermal cycler with heated cover (Bio-Rad, Hercules, CA, USA) in the $25-\mu \mathrm{L}$ reaction solution. The composition of reaction solution, PCR profiles, and electrophoretic separation of amplified DNA fragments were described in LemaRumińska et al. (2019). Gel images were recorded using a GelDoc XR + Gel Photodocumentation System (Bio-Rad, Hercules, CA, USA) UV transilluminator with Image Lab 4.1 software. Molecular weights of the fragments were estimated using a 100-5000 bp DNA molecular marker (Gene Ruler ${ }^{\mathrm{TM}}$ Express DNA Ladder, Thermo Fisher Scientific, Waltham, MA, USA).
Fig. 1 Graphs of DLS size distribution and STEM images of silver nanoparticles (figures by courtesy of Nanoparticles Innovation NPIN s.c., Łódź, Poland)

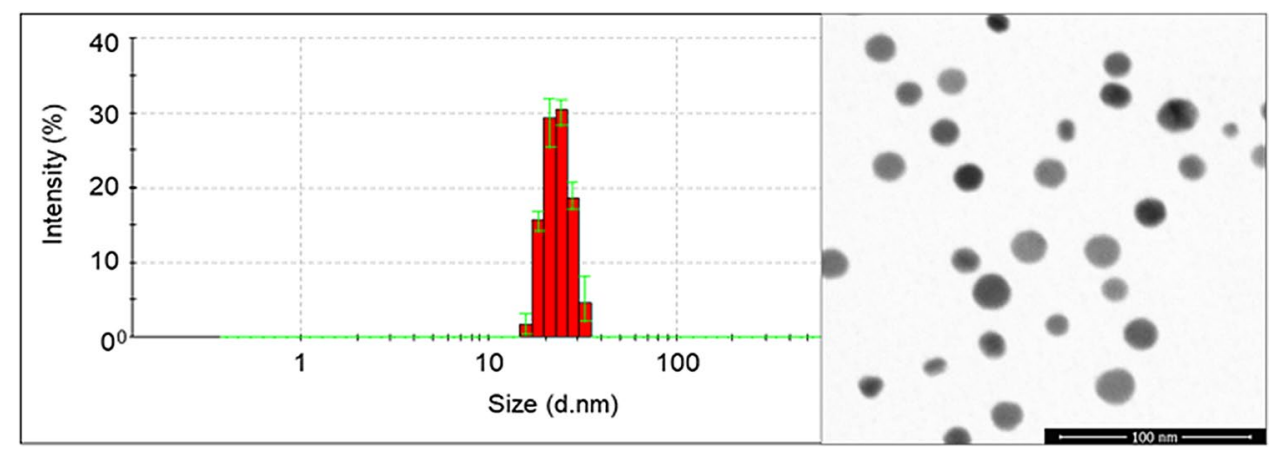


The banding patterns were recorded as $0-1$ binary matrices, where " 1 " indicates the presence and " 0 " the absence of a given fragment followed by statistical analysis. For every primer tested, the numbers of monomorphic, polymorphic (present in the electrophoretic profile of more than one individual) and specific/unique loci (present in the electrophoretic profile of a single individual) were counted.

\section{Acclimatization, ex vitro cultivation, and phenotype evaluation}

For acclimatization, rooted plantlets were planted into plastic cuvettes filled with a disinfected $(0.2 \%, w / v$, Benlate 50WP; DuPont, Wilmington, DE, USA) mixture of peat substrate (Hartman, Poznań, Poland) and perlite (Perlit, Šenov u Nového Jičína, The Czech Republic) $(2: 1, v / v)$. Acclimatization was performed for two weeks in June in natural light conditions in a glasshouse. Plants were regularly sprayed with water and covered with perforated foil. Next, the plants were transferred to plastic pots filled with peat substrate (Hartman, Poznań, Poland), cultivated in the greenhouse in natural photoperiod by applying the standard method, i.e. one stem with a single inflorescence, and brought to full flowering.

Observation was done to identify the mutants (plants of changed morphological traits) and mutations corresponding to the altered traits. The frequency of mutant and mutation occurrence was determined against the total number of flowering plants. The mutants were distinguished by defining the color and shape of the inflorescences of the standard, control, and plants treated with AgNPs. The color of the inner and outer sides of ligulate florets of fully-developed inflorescences was established using the Royal Horticultural Society Colour Chart catalog (RHSCC 1966).

\section{Biochemical array}

Chlorophylls and carotenoids were extracted from in vitro regenerated calli and adventitious shoots in the 10th week of culture, as described by Lichtenthaler (1987) using $100 \%$ acetone (Chemia, Bydgoszcz, Poland) and $100 \mathrm{mg}$ tissues samples in six repetitions. Analysis of the total phenolic content was performed according to the Folin-Ciocalteau procedure (Waterhouse 2001) using $200 \mathrm{mg}$ shoot samples in six repetitions. The total phenolic content was calculated using gallic acid (Sigma-Aldrich, St. Louis, MO, USA) as the calibration standard.

The analysis of pigments in ligulate florets in the standard and in six ex vitro-grown mutants was performed. Three samples from each tested inflorescence at the full flowering stage were prepared. Carotenoids were extracted from $100 \mathrm{mg}$ samples of ligulate florets with the use of $100 \%$ acetone (Chemia, Bydgoszcz, Poland) (Lichtenthaler 1987).
Anthocyanins were extracted using $200 \mathrm{mg}$ ligulate florets samples and methanol containing $1 \% \mathrm{HCl}(v / v)$ (Chemia, Bydgoszcz, Poland) according to the Harborne (1967) method.

The spectrophotometric analysis of extracts was performed in a two-beam spectrophotometer UV-VIS 1601PC (SHIMADZU, Kioto, Japan) at specific wavelengths $\left(\lambda_{\max }\right)$ : for anthocyanins (cyanidin-3-glucoside) at $530 \mathrm{~nm}$, for chlorophyll $a$ and $b$ at 645 and $662 \mathrm{~nm}$, for carotenoids at $470 \mathrm{~nm}$, and for phenolics at $765 \mathrm{~nm}$, respectively. The content of pigments and phenolics was calculated per gram of fresh matter.

\section{Statistical analysis}

The experiment was set up in a completely randomized design. Data were statistically verified using Statistica 12.0 (StatSoft Polska, Cracow, Poland) software. The analysis of variance (ANOVA) was performed and means were compared with Fisher's exact test at the significance level of $p \leq 0.05$. To obtain the normal distribution of the data expressed as a percentage, the Freeman-Tukey transformation was used. Tables with results provide real, untransformed numerical data, with the alphabet indicating the homogeneous groups.

The coefficient of genetic distance based on Nei and $\mathrm{Li}$ algorithm (1979) was calculated by a comparison of the predominant band pattern of the standard plants with the band patterns of the adventitious shoots regenerated from the explants treated with AgNPs. The dendrograms were created based on agglomerative hierarchical clustering (AHC) with unweighted pair group average method (UPGMA) using Statistica 12.0. Population groups were distinguished based on the analysis of molecular variance (AMOVA) and principle cluster analysis (PCoA) estimates using GeneAlEx 6.5 software (Peakall and Smouse 2012) with the assumption that AgNPs-treated and standard plants are two separate populations.

\section{Results}

\section{Adventitious organogenesis and biochemical stability of in vitro-produced calli and shoots}

During the first week of culture, all of the inoculated internodes grew visually longer and swollen, particularly in the area of cutting. In the same week, the formation of green callus began. Starting from the third week, browning of calli was observed, especially in internodes cultured on media with the addition of AgNPs. The first adventitious shoots appeared in the third week of culture on control explants and explants cultured on media with AgNPs (Fig. 2). All shoots 


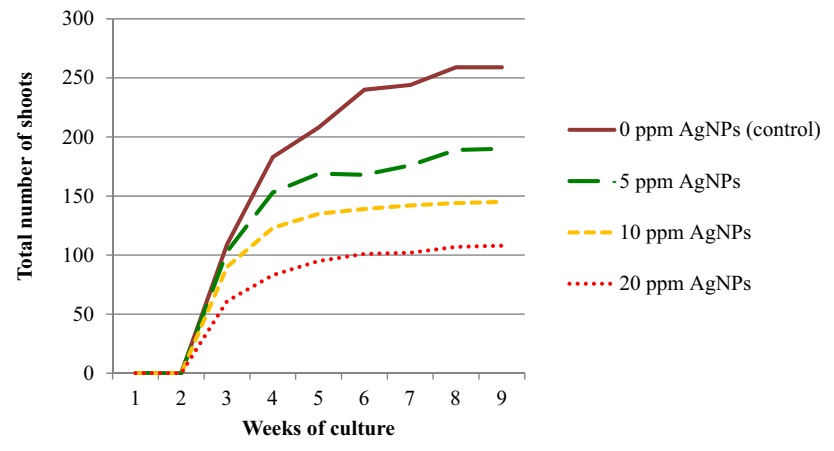

Fig. 2 Dynamics of adventitious shoots regeneration on Chrysanthemum $\times$ grandiflorum 'Lilac Wonder' internodes cultured on the modified MS medium with AgNPs (0-20 ppm), $0.6 \mathrm{mg} \mathrm{L}^{-1} \mathrm{BAP}$ and $2 \mathrm{mg}$ $\mathrm{L}^{-1}$ IAA regenerated indirectly via callus (Fig. 3). Control explants regenerated most shoots between the third and sixth week of culture. The highest increase in the number of shoots produced on internodes cultured on media with the addition of AgNPs was recorded between the third and fifth week, regardless of nanoparticle concentration.

Silver nanoparticles treatment affected the explants capability to form callus and shoots (Table 1; Fig. 3). The share of internodes proliferating calli/shoots was the highest in the control object and the lowest on the medium with 20 ppm AgNPs. Similarly, internodes treated with 20 ppm AgNPs produced the lowest number of shoots per inoculated explant, while the mean number of shoots on control internodes was significantly higher. Explants inoculated on media supplemented with silver nanoparticles at the concentration
Fig. 3 Adventitious shoot regeneration on Chrysanthemum $\times$ grandiflorum 'Lilac Wonder' internodes cultured on the modified MS medium with AgNPs (0-20 ppm), 0.6 mg $\mathrm{L}^{-1}$ BAP and $2 \mathrm{mg} \mathrm{L}^{-1}$ IAA in the fourth and eighth week of culture; $b a r=1 \mathrm{~cm}$

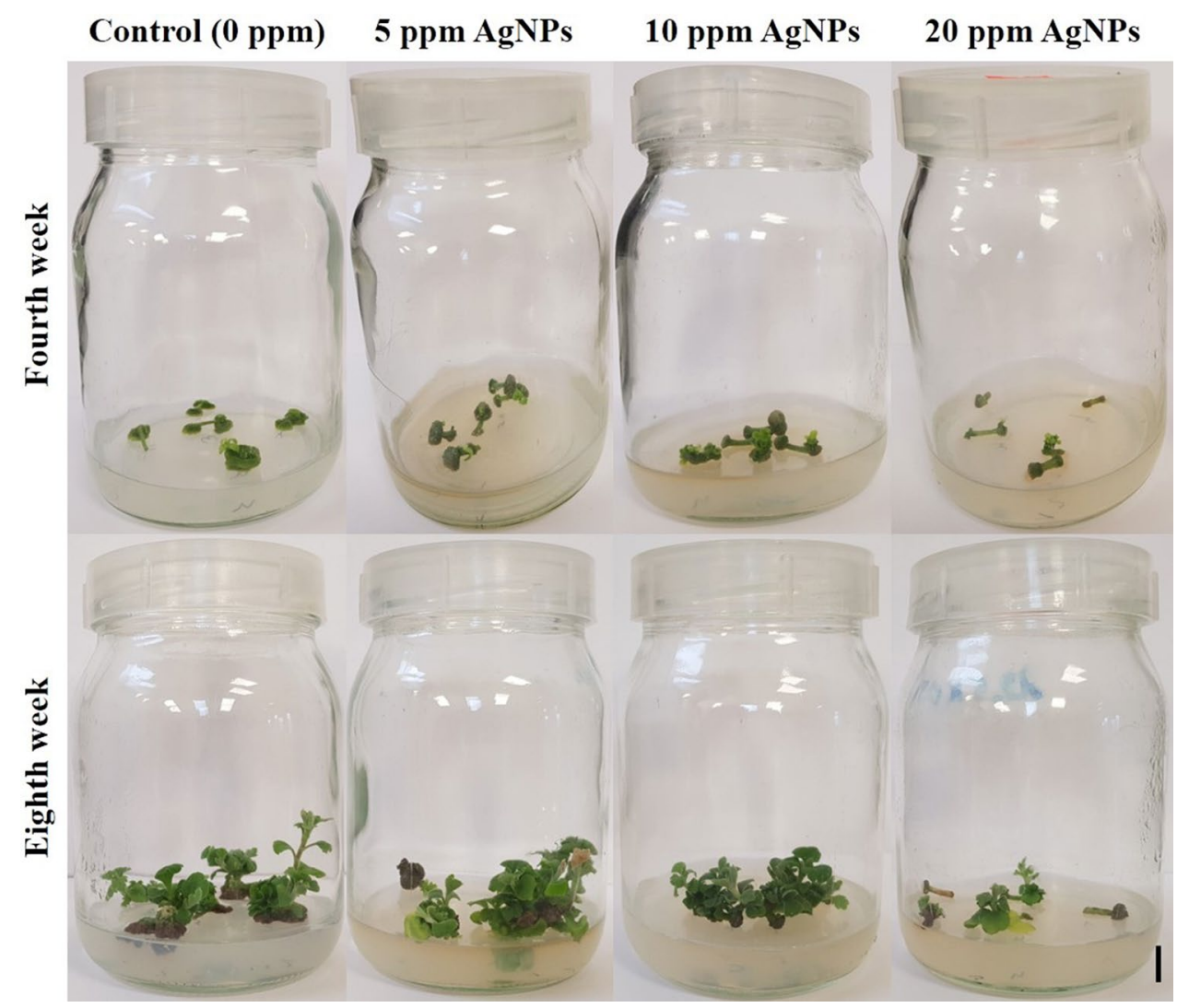

Table 1 Regeneration of callus and adventitious shoots on Chrysanthemum $\times$ grandiflorum 'Lilac Wonder' internodes cultured for 10 weeks on the modified MS medium with AgNPs (0-20 ppm), $0.6 \mathrm{mg} \mathrm{L}^{-1}$ BAP and $2 \mathrm{mg} \mathrm{L}^{-1}$ IAA

\begin{tabular}{llll}
\hline Concentration of AgNPs & $\%$ of explants forming callus & $\%$ of explants forming shoots & $\begin{array}{l}\text { Mean number of } \\
\text { shoots per explant }\end{array}$ \\
\hline $0 \mathrm{ppm}$ (control) & $100.0 \mathrm{a}^{*}$ & $94.0 \mathrm{a}$ & $5.58 \pm 0.75 \mathrm{a}$ \\
$5 \mathrm{ppm}$ & $86.0 \mathrm{ab}$ & $80.0 \mathrm{ab}$ & $4.40 \pm 1.26 \mathrm{ab}$ \\
$10 \mathrm{ppm}$ & $78.0 \mathrm{ab}$ & $74.0 \mathrm{ab}$ & $3.34 \pm 2.12 \mathrm{ab}$ \\
$20 \mathrm{ppm}$ & $50.0 \mathrm{~b}$ & $46.0 \mathrm{~b}$ & $2.60 \pm 3.27 \mathrm{~b}$ \\
\hline
\end{tabular}

*Values represent means \pm standard deviation, five repetitions were included, ten explants in each. Means in columns followed by the same letter do not differ significantly at $\mathrm{p} \leq 0.05$ (Fisher's test) 
of 5 or $10 \mathrm{ppm}$ did not statistically differ from the control object or the 20 ppm AgNPs-treatment in terms of the efficiency of shoot regeneration.

Calli regenerated on control and AgNPs-treated internodes did not differ in terms of the content of chlorophyll $a$, chlorophyll $b$, total content of chlorophylls $(a+b)$, and chlorophyll $a / b$ ratio (Table 2 ). A higher carotenoid concentration was found in calli proliferated on internodes treated with $20 \mathrm{ppm}$ AgNPs compared to the other experimental objects. Adventitious shoots regenerated on the control medium and with 5 ppm AgNPs produced more chlorophyll $a$ and $(a+b)$ than adventitious shoots regenerated on the medium with 10 or $20 \mathrm{ppm}$ AgNPs. No differences were found in shoots for the chlorophyll $a / b$ ratio and carotenoid content. The application of silver nanoparticles, irrespective of concentration, did not influence the content of total phenolic compounds neither in the regenerated calli nor adventitious shoots.

\section{Genetic stability of in vitro-produced chrysanthemums}

Diverse results were found with the two marker systems: RAPD and ISSR. A total of 2777 scorable bands, in the range of 330-3080 bp, were detected by five RAPD primers in 85 AgNPs-treated plants (Table 3). The highest number of loci (11) was amplified with the R-E primer, while six loci were found with the R-B primer. Primers R-A and $\mathrm{R}-\mathrm{B}$ did not detect any polymorphisms. On the other hand, 90.0\% loci were polymorphic (in 5 different genotypes) according to the R-C primer (Fig. 4). A total of 12 polymorphic plants (all obtained after AgNPs treatment) were detected within the RAPD analysis. No polymorphisms were found in the standard plants. The ISSR marker system generated fewer products than RAPD; 1953 scorable bands, in the range of 326-4764 bp (Table 3). The highest number of loci (7) was found with the I-A primer (Fig. 4), while primers I-B, I-C, and I-E amplified four loci. Polymorphic loci were detected only by the I-A primer. No specific/unique amplicons were detected in the study. Polymorphic bands were found in nine AgNPs-treated plants, within seven genotypes, but not in the standard.

Various primers and marker systems detected variation in different plants, except for one individual (no. 33) reported as polymorphic by both RAPD and ISSR. Cluster analysis of the RAPD marker system showed that the tested specimens were grouped into two clusters (Fig. 5). The highest genetic distance (2.8) was found for individual no. 61 . The remaining plants were grouped into the second cluster, which was further divided into smaller sub-clusters, with the largest one containing 98 individuals. The genetic distance between individuals in the second cluster ranged from 0.0 (in most cases) to 2.0. As for the ISSR data, individual no. 26 was the most distinctive (genetic distance: 1.4) and placed in a separate cluster (Fig. 5). The remaining 109 plants were grouped in the second cluster, divided into five sub-clusters. The genetic distance between all eight polymorphic individuals and the predominant reference was identical-1.0.

The PCoA analysis arranged the studied plants in four (RAPD) and three (ISSR) groups of uneven size (Fig. 6). However, various genotypes were placed in those groups for RAPD and ISSR markers, respectively. According to the AMOVA analysis of RAPD data, treatment with AgNPs had a significant influence on the occurrence of genetic variability in chrysanthemum 'Lilac Wonder'. On the other hand, no such influence was found with the ISSR markers.

Table 2 Content of pigments and phenolic compounds $\left(\mathrm{mg} \mathrm{g}^{-1}\right.$ fresh matter) in calli and adventitious shoots regenerated from internodes of Chrysanthemum $\times$ grandiflorum 'Lilac Wonder' after 10 weeks of

culture on the modified MS medium with AgNPs (0-20 ppm), $0.6 \mathrm{mg}$ $\mathrm{L}^{-1} \mathrm{BAP}$ and $2 \mathrm{mg} \mathrm{L}^{-1}$ IAA

\begin{tabular}{lllllll}
\hline Concentration of AgNPs & Chlorophyll $a$ & Chlorophyll $b$ & Chlorophyll $a / b$ ratio & Chlorophylls $(a+b)$ & Carotenoids & Phenolic compounds \\
\hline Calli & & & & & & \\
$0 \mathrm{ppm}$ (control) & $0.12 \pm 0.06 \mathrm{a}^{*}$ & $0.10 \pm 0.11 \mathrm{a}$ & $2.02 \pm 1.75 \mathrm{a}$ & $0.22 \pm 0.17 \mathrm{a}$ & $0.04 \pm 0.01 \mathrm{~b}$ & $11.88 \pm 1.13 \mathrm{a}$ \\
$5 \mathrm{ppm}$ & $0.21 \pm 0.09 \mathrm{a}$ & $0.23 \pm 0.14 \mathrm{a}$ & $1.04 \pm 0.29 \mathrm{a}$ & $0.44 \pm 0.23 \mathrm{a}$ & $0.04 \pm 0.01 \mathrm{~b}$ & $14.92 \pm 4.96 \mathrm{a}$ \\
$10 \mathrm{ppm}$ & $0.15 \pm 0.03 \mathrm{a}$ & $0.12 \pm 0.04 \mathrm{a}$ & $1.28 \pm 0.29 \mathrm{a}$ & $0.27 \pm 0.07 \mathrm{a}$ & $0.03 \pm 0.01 \mathrm{~b}$ & $13.33 \pm 1.70 \mathrm{a}$ \\
$20 \mathrm{ppm}$ & $0.20 \pm 0.08 \mathrm{a}$ & $0.19 \pm 0.14 \mathrm{a}$ & $1.44 \pm 0.73 \mathrm{a}$ & $0.39 \pm 0.22 \mathrm{a}$ & $0.05 \pm 0.01 \mathrm{a}$ & $12.13 \pm 2.64 \mathrm{a}$ \\
Adventitious shoots & & & & & & \\
$0 \mathrm{ppm}$ (control) & $0.50 \pm 0.09 \mathrm{ab}$ & $0.30 \pm 0.05 \mathrm{ab}$ & $1.61 \pm 0.19 \mathrm{a}$ & $0.81 \pm 0.13 \mathrm{ab}$ & $0.13 \pm 0.03 \mathrm{a}$ & $11.03 \pm 6.88 \mathrm{a}$ \\
$5 \mathrm{ppm}$ & $0.53 \pm 0.22 \mathrm{a}$ & $0.34 \pm 0.15 \mathrm{a}$ & $1.61 \pm 0.28 \mathrm{a}$ & $0.87 \pm 0.36 \mathrm{a}$ & $0.12 \pm 0.05 \mathrm{a}$ & $11.45 \pm 7.14 \mathrm{a}$ \\
$10 \mathrm{ppm}$ & $0.32 \pm 0.06 \mathrm{c}$ & $0.19 \pm 0.05 \mathrm{~b}$ & $1.70 \pm 0.36 \mathrm{a}$ & $0.51 \pm 0.10 \mathrm{c}$ & $0.09 \pm 0.03 \mathrm{a}$ & $7.77 \pm 3.95 \mathrm{a}$ \\
$20 \mathrm{ppm}$ & $0.34 \pm 0.13 \mathrm{c}$ & $0.19 \pm 0.12 \mathrm{~b}$ & $2.29 \pm 0.96 \mathrm{a}$ & $0.53 \pm 0.25 \mathrm{c}$ & $0.09 \pm 0.04 \mathrm{a}$ & $6.53 \pm 2.29 \mathrm{a}$ \\
\hline
\end{tabular}

*Values represent means \pm standard deviation, six repetitions were included. Means in columns followed by the same letter do not differ significantly at $\mathrm{p} \leq 0.05$ (Fisher's test) 


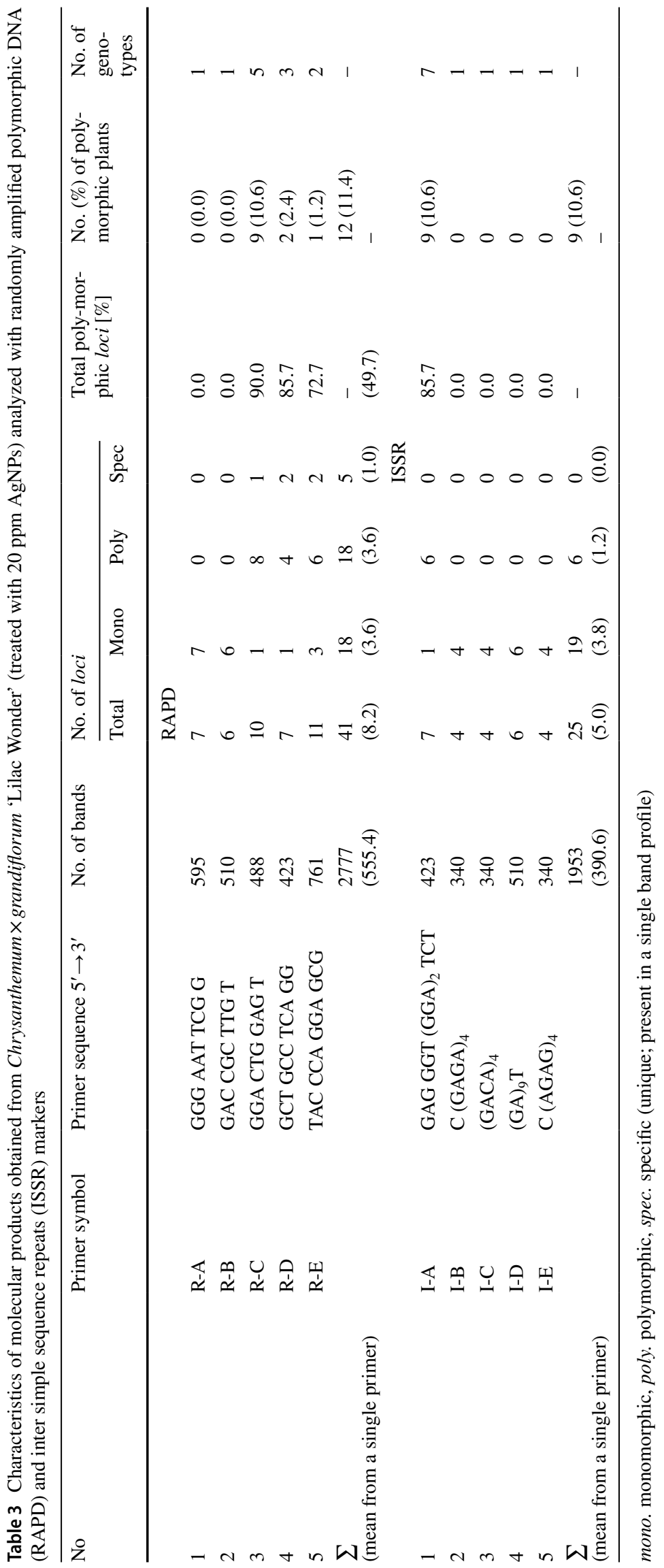


Fig. 4 Example RAPD (A) and ISSR (B) band profiles of Chrysanthemum $\times$ grandiflorum received as a result of electrophoresis of the DNA amplification products obtained with the $\mathrm{R}-\mathrm{C}$ and I-A primers. Outermost lanes (wm) are DNA bp weight markers; $1,2,3, \ldots$-are numbers of plants (1-3 standard plants, 4-38 adventitious shoots produced after $20 \mathrm{ppm}$ AgNPs treatment); arrows point to profiles that differ from the reference

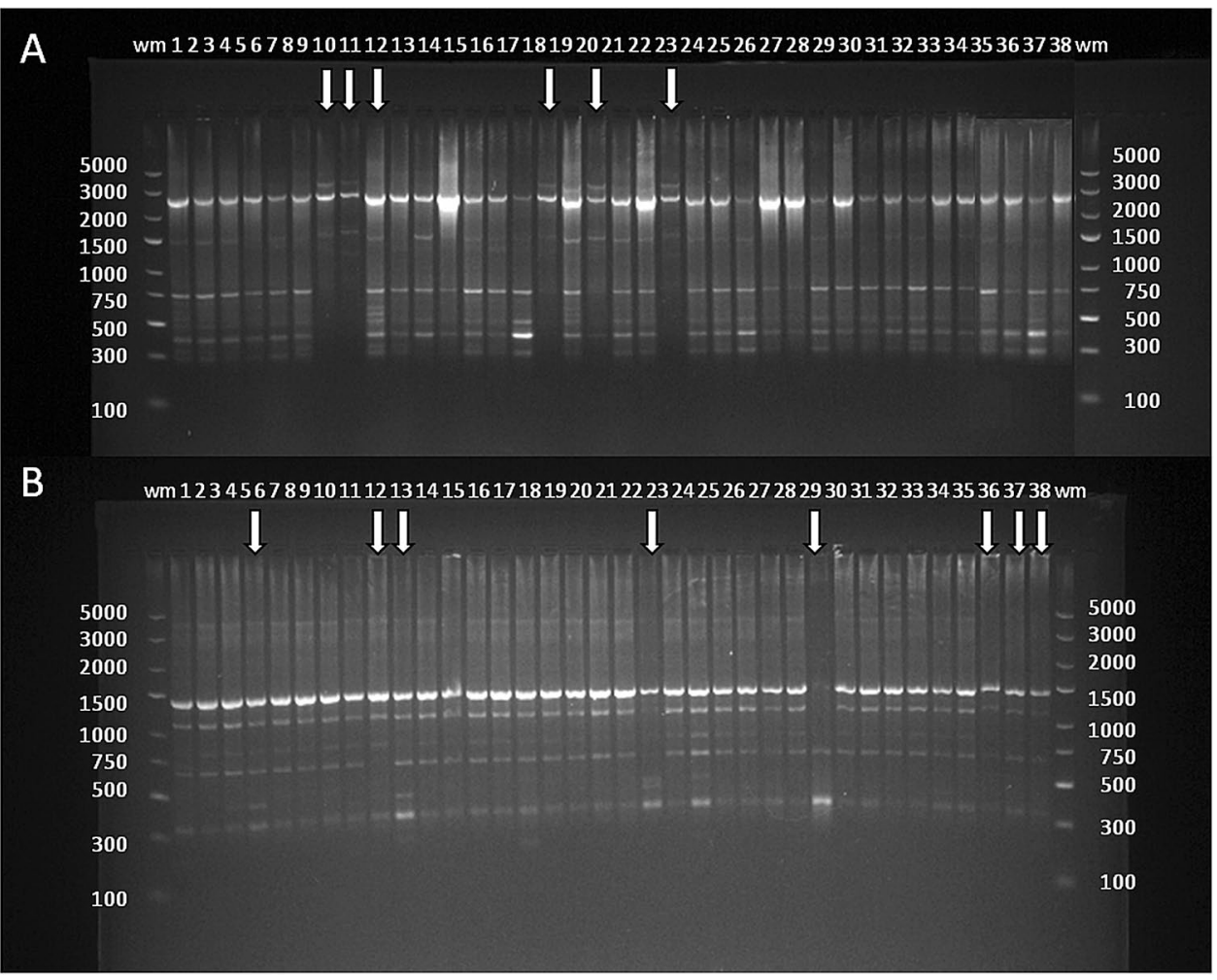

\section{Phenotype evaluation and biochemical stability of ex vitro-cultivated chrysanthemums}

Rooting and acclimatization were $100 \%$ successful for the standard, control object, and the AgNPs-derived adventitious shoots (Table 4). Flowering occurred in 92.9-98.0\% chrysanthemums, and was not significantly affected by AgNPs treatment (Table 4). Plants of the standard and after 0-5 ppm AgNPs-treatment formed typical pink, full, and semi-ball inflorescences (Tables 4, 5). One mutant was found among flowering 10 ppm AgNPs-derived plants (Individual no. 1). The mutation was phenotypically manifested as the change of inflorescence color-from pink to pink-gold (Tables 4, 5; Fig. 7). On the other hand, five mutants with altered phenotype traits were observed among $20 \mathrm{ppm}$ AgNPs-treated chrysanthemums. The frequency of mutant and mutation occurrence in this experimental object amounted to $6.3 \%$ and $8.9 \%$, respectively. Most of the variations were related to inflorescence color change (in six plants)—from pink to light pink, burgundy-gold, and dark pink. Two of those plants additionally had a changed inflorescence shape-Individual no. 63 (semi-full with the visible disc of ray florets) and Individuals no. 82 (irregular). Individual no. 71 was of chimeric structure, in which part of one ligulate floret was covered with a narrow sector of red color.

The spectrophotometric analysis of pigment extracts from ligulate florets showed that changes in the color of mutant inflorescences were a result of both quantitative and qualitative differences in the content of pigments (Table 5; Fig. 7). Unlike the standard, inflorescences of Individual no. 1 (from $10 \mathrm{ppm}$ AgNPs treatment) and Individual no. 77 (20 ppm AgNPs) contained carotenoids. In three plants (one from $10 \mathrm{ppm}$ treatment and two from $20 \mathrm{ppm}$ ), an increase in the content of anthocyanins was reported. Ligulate florets of Individuals no. 1, 63, and 71 (all from 20 ppm AgNPs treatment) were characterized by a lower content of anthocyanins compared to the standard.

\section{Discussion}

\section{Impact of AgNPs on the morphogenetic and biochemical events in chrysanthemum in vitro}

The present study indicates a significant impact of silver nanoparticles on the regeneration capability of chrysanthemum explants. None of the AgNPs treatments improved the regeneration efficiency in 'Lilac Wonder' cultivar compared with the untreated control. Higher AgNPs concentration $(20 \mathrm{ppm})$ even inhibited callogenesis and caulogenesis in vitro, possibly as a result of cell damage or cell-cycle arrest not observed at lower concentrations (5-10 ppm) (Ghosh et al. 2016). Similar morphogenesis-inhibitoryeffects were reported in chrysanthemum explants treated with physical mutagens, such as $\mathrm{X}$ or gamma radiation (Zalewska et al. 2010, 2011). Application of 40 and 60 ppm 

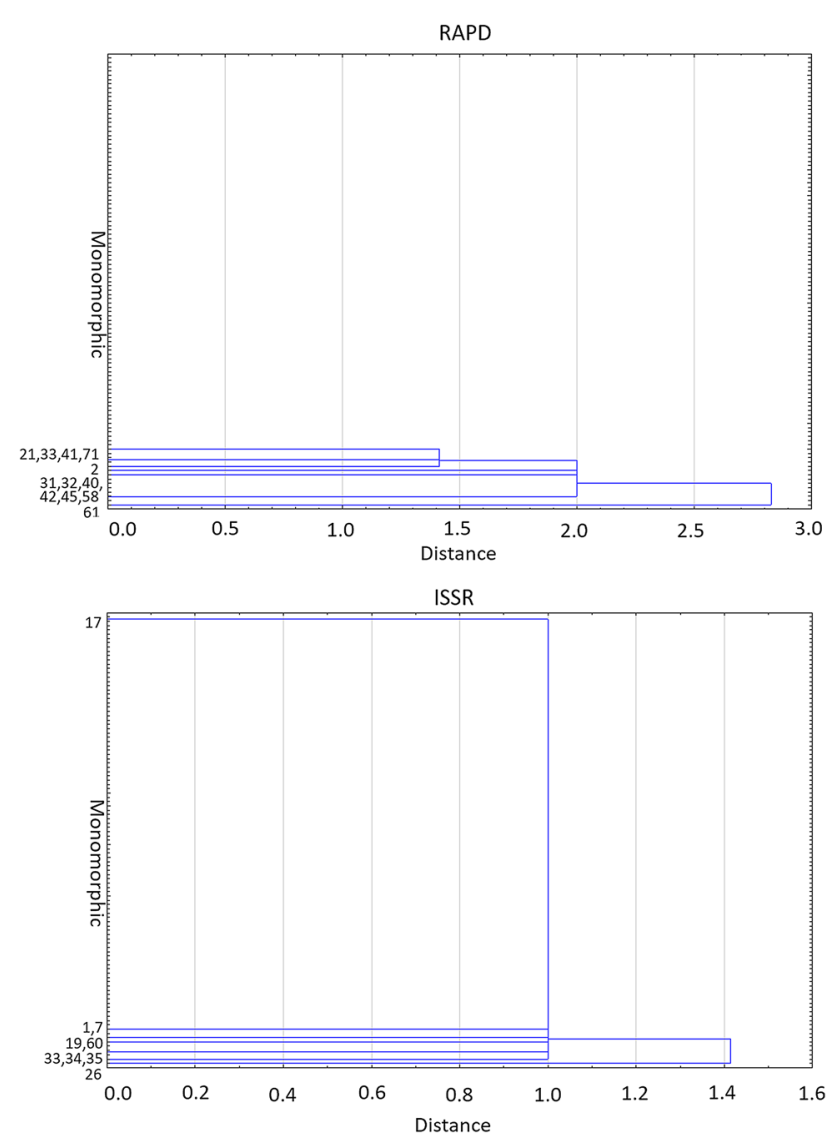

Fig. 5 Dendrograms based on the estimation of genetic distance coefficient and UPGMA clustering presenting the relationships between 20 ppm AgNPs-treated (1-85) and standard plants (86-110), revealed by the randomly amplified polymorphic DNA (RAPD) and inter simple sequence repeats (ISSR) analyses. Plants representing the same band pattern as the predominant standard are collected within a single group named 'Monomorphic'. The scale shows a real genetic distance value

AgNPs resulted in swelling, length reduction, and deformation of calli cells in two wheat (Triticum aestivum L.) cultivars (Barbasz et al. 2016). On the other hand, silver and gold nanoparticles (10 ppm) improved the efficiency of Cape Primrose micropropagation (Tymoszuk and Miler 2019). As for barley (Hordeum vulgare L.) tissue culture, a positive effect of $\mathrm{TiO}_{2}$ nanoparticles on the fresh weight of callus was found (Mandeh et al. 2012). This underlines a species-, NPs-type- and concentration-dependent effect of nanoparticles reported also by other authors (Dietz and Herth 2011; Syu et al. 2014). To summarize, an increase in AgNPs content over $20 \mathrm{ppm}$ is not recommended for chrysanthemum micropropagation, but might be useful in mutation induction as shown in this study.

The increase in carotenoid content in callus and decline in chlorophyll $a$ and $(a+b)$ concentrations in adventitious shoots regenerated after $20 \mathrm{ppm}$ treatment may be a result of oxidative stress induced by AgNPs (Jaleel et al. 2009).
The toxicity of nanoparticles can be associated with the release of toxicants from their surface, such as metal ions or residues after synthesis (Barbasz et al. 2016). To cope with oxidative stress, plants have developed several strategies to scavenge free reactive oxygen species (ROS) produced in excess under stress conditions in cells. Nonenzymatic strategies are based on the increased biosynthesis of small molecules with antioxidant properties, e.g. plastid localized carotenoids (Dumont and Rivoal 2019; Yan and Chen 2019). This explains the increase in carotenoid concentration in callus after application of the highest (20 ppm) AgNPs concentration in the current study. Similarly, an increase in shoot carotenoid content as a result of AgNPs application was found in rice (Oryza sativa L.), suggesting that carotenoids perform an important function in the reduction of ROS effects caused by nanoparticles (Mirzajani et al. 2013).

Chlorophyll, on the other hand, is the most non-stable pigment within the plant. During stress, inhibition in the activity of enzymes, such as $\delta$-aminolevulinic acid dehydratase and protochlorophyllide reductase, key to chlorophyll biosynthesis is found (Van Assche and Clijsters 1990). This may explain the observed variation in its content. A decline in chlorophyll $a$ and chlorophyll $b$ content was also reported by Fayez et al. (2017) in barley plants after application of 50 and 100 ppm AgNPs. Exposure to silver nanoparticles reduced also the total chlorophyll content in mung bean (Vigna radiata (L.) R. Wilczek), filed mustard (Brassica campestris L.) (Mazumdar 2014), and an aquatic plant species Lemna gibba L. (Dewez et al. 2018).

Polyphenols are a marker of oxidative stress in plants and part of a defense system, associated with the activity of ROS (Noctor et al. 2015). The significance of phenolic compounds in the protection against AgNPs-induced oxidative stress was reported in barley (Fayez et al. 2017) and water hyssop (Bacopa monnieri (Linn.) Wettst.) (Krishnaraj et al. 2012). Surprisingly, in the current study, the level of phenolic compounds in 10-week-old calli and shoots was constant, irrespective of AgNPs treatment. This suggests that stress response related to phenolic compounds biosynthesis in the tested cultivar might have been short and reversible, as suggested by Cvjetko et al. (2018). Another explanation is that the applied concentrations of AgNPs were too low to induce their production. According to Yasur and Rani (2013), phenols content in roots and shoots of 7-day-old castor (Ricinus communis L.) seedlings increased with the increase in the concentration of AgNPs up to 500 and $1000 \mathrm{ppm}$, respectively, and then, decreased gradually at the concentrations of 2000 and $4000 \mathrm{ppm}$. Similarly, increased phenolic compound content in 3-week-old Nigella arvensis L. seedlings was observed only after the treatment with high concentrations of $\mathrm{Al}_{2} \mathrm{O}_{3} \mathrm{NPs}(100-2500 \mathrm{ppm})$ and NiONPs (2500 ppm) (Chahardoli et al. 2020). 
Fig. 6 Graphs of principal coordinates analysis (PCoA) of Chrysanthemum $\times$ grandiflorum plants obtained after $20 \mathrm{ppm}$ AgNPs treatment (1-85) and in standard (86-110), based on randomly amplified polymorphic DNA (RAPD) and inter simple sequence repeats (ISSR) analyses. Plants representing the same band pattern as the predominant standard are collected within a single group named 'Monomorphic'
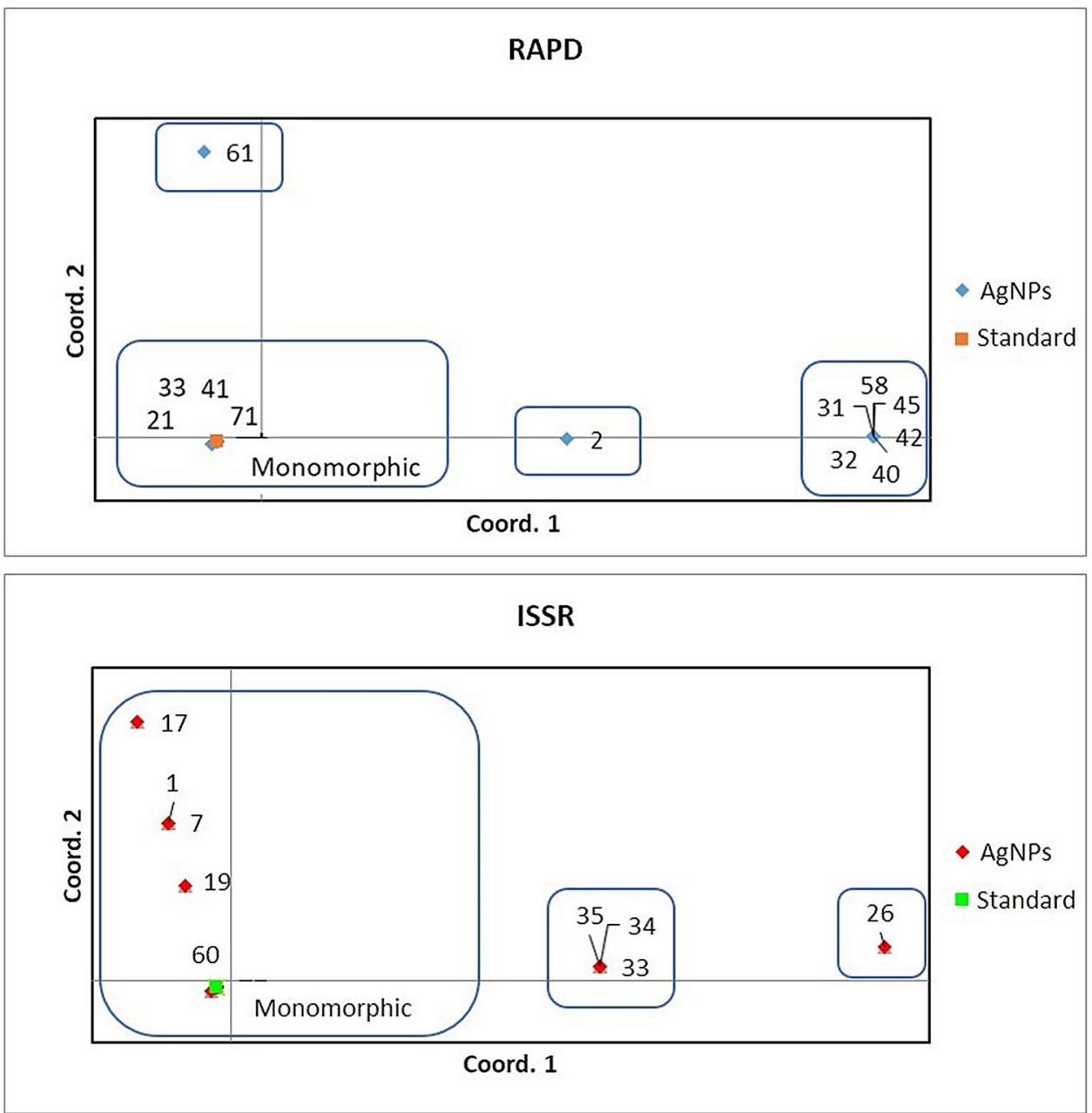

Table 4 Rooting, acclimatization, and flowering in Chrysanthemum $\times$ grandiflorum 'Lilac Wonder' as a result of AgNPs treatment

\begin{tabular}{|c|c|c|c|c|c|c|c|}
\hline Treatment & $\begin{array}{l}\text { No. of shoots trans- } \\
\text { ferred on rooting } \\
\text { medium }\end{array}$ & $\begin{array}{l}\text { No. of acclimatized and } \\
\text { ex vitro cultivated shoots }\end{array}$ & $\begin{array}{l}\text { No. }(\%) \text { of } \\
\text { flowering } \\
\text { shoots }\end{array}$ & $\begin{array}{l}\text { No. of } \\
\text { mutants }\end{array}$ & $\begin{array}{l}\text { Frequency of } \\
\text { mutants (\%) }\end{array}$ & $\begin{array}{l}\text { No. of } \\
\text { mutations }\end{array}$ & $\begin{array}{l}\text { Frequency } \\
\text { of mutations } \\
\text { (\%) }\end{array}$ \\
\hline Standard & 25 & 25 & $24\left(96.0 a^{*}\right)$ & 0 & 0 & 0 & 0 \\
\hline $0 \mathrm{ppm}$ (control) & 100 & 100 & 98 (98.0a) & 0 & 0 & 0 & 0 \\
\hline 5 ppm & 100 & 100 & 96 (96.0a) & 0 & 0 & 0 & 0 \\
\hline $10 \mathrm{ppm}$ & 100 & 100 & 98 (98.0a) & 1 & 1.0 & 1 & 1.0 \\
\hline $20 \mathrm{ppm}$ & 85 & 85 & 79 (92.9a) & 5 & 6.3 & 7 & 8.9 \\
\hline
\end{tabular}

*Means in columns followed by the same letter do not differ significantly at $\mathrm{p} \leq 0.05$ (Fisher's test). Standard—plants propagated via the single node method on the PGRs-free medium. Control—adventitious shoots regenerated on the AgNPs-free medium

\section{Genetic and phenotype stability of AgNPs-treated chrysanthemums}

In the current study, a total of 20 plants had an altered DNA sequence, i.e. $23.5 \%$ of chrysanthemums regenerated from 20 ppm AgNPs-treated explants. Among those 20 individuals, only one was detected by both RAPD and ISSR markers. This underlines the necessity of using more than one marker system in breeding studies. RAPD markers were previously applied to successfully distinguish even closely related chrysanthemum cultivars (Minano et al. 2009). Also in the present study, RAPDs were more effective in detecting variation ( 3 out of 5 primers detected polymorphisms in 12 specimens) compared to ISSRs (only one primer). Those results coincide with the findings by Lema-Rumińska et al. (2019) and Kulus et al. (2019) in other members of the Asteraceae family. On the other hand, in the Poaceae family-Hordeum vulgare L. (Fernández et al. 2002) and Oryza granulata Nees 
Table 5 Inflorescence characteristics and composition of pigments in ligulate florets of Chrysanthemum $\times$ grandiflorum 'Lilac Wonder' and its mutants obtained as a result of AgNPs treatment

\begin{tabular}{|c|c|c|c|c|c|}
\hline \multirow[t]{2}{*}{ Treatment } & \multicolumn{3}{|l|}{ Inflorescence characteristic } & \multicolumn{2}{|c|}{$\begin{array}{l}\text { Content of pigments in ligulate } \\
\text { florets ( } \mathrm{mg} \mathrm{g}^{-1} \text { fresh matter) }\end{array}$} \\
\hline & Color & RHSCC color code & Shape & Anthocyanins & Carotenoids \\
\hline Lilac Wonder standard & Pink & $70 \mathrm{C} / 69 \mathrm{~A}^{*}$ & Full, semi-ball & 0.63 & - \\
\hline Individual no. 1 (10 ppm AgNPs) & Pink-gold & $58 \mathrm{~B} / 163 \mathrm{D}$ & Full, semi-ball & 0.64 & 0.28 \\
\hline Individual no. 1 (20 ppm AgNPs) & Light pink & $63 \mathrm{C} / 62 \mathrm{D}$ & Full, semi-ball & 0.17 & - \\
\hline Individual no. 63 (20 ppm AgNPs) & Light pink & $65 \mathrm{~A} / 62 \mathrm{C}$ & Semi-full & 0.25 & - \\
\hline Individual no. 71 (20 ppm AgNPs) & Light pink with a red stripe & $68 \mathrm{~B} / 69 \mathrm{D}$ & Full, semi-ball & 0.41 & - \\
\hline Individual no. 77 (20 ppm AgNPs) & Burgundy-gold & $179 \mathrm{~A} / 164 \mathrm{C}$ & Full, semi-ball & 1.36 & 0.45 \\
\hline Individual no. 82 (20 ppm AgNPs) & Dark pink & $70 \mathrm{~A} / 62 \mathrm{~B}$ & Full, irregular & 0.67 & - \\
\hline
\end{tabular}

Standard-plants propagated via the single node method on the PGRs-free medium

*Inner/outer side of ligulate florets

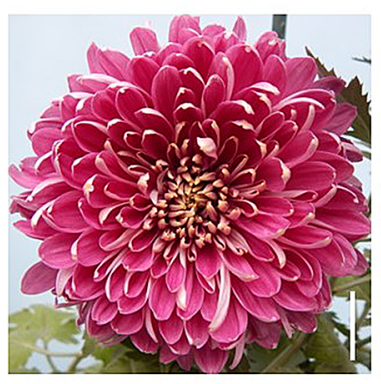

Lilac Wonder standard

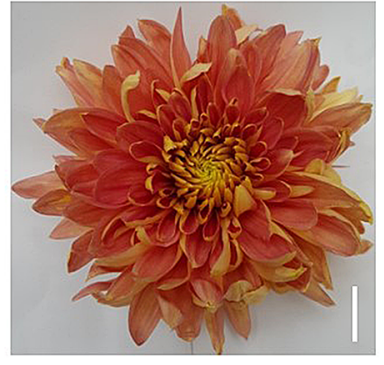

Individual no. 1 (10 ppm AgNPs)

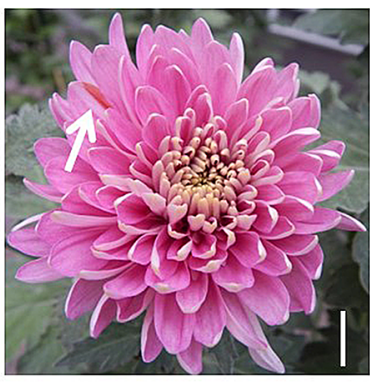

Individual no. 71

(20 ppm AgNPs)

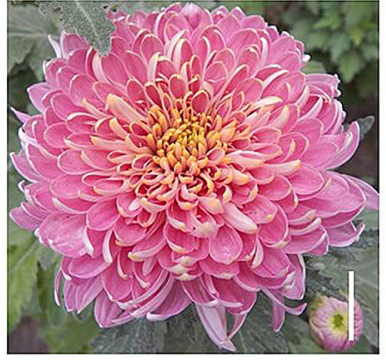

Individual no. 1

(20 ppm AgNPs)

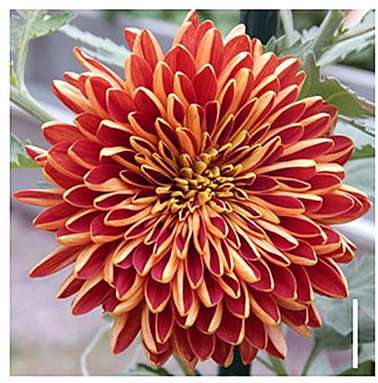

Individual no. 77

(20 ppm AgNPs)

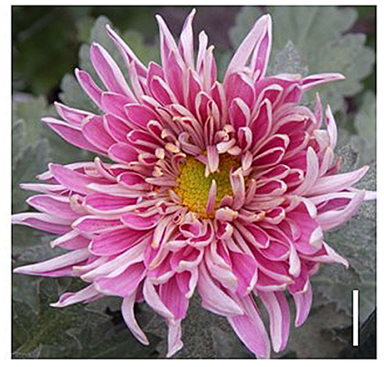

Individual no. 63

(20 ppm AgNPs)

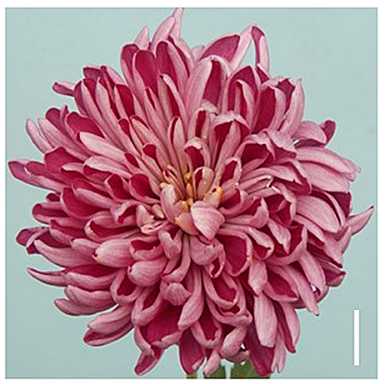

Individual no. 82

(20 ppm AgNPs)

Fig. 7 Chrysanthemum $\times$ grandiflorum 'Lilac Wonder' and its mutants obtained as a result of AgNPs application at different concentrations; arrow indicates a chimeric ligulate floret; $b a r=2 \mathrm{~cm}$

et Arn. ex Watt (Qian et al. 2001), the ISSR markers were more useful in screening polymorphisms than RAPDs. This suggests botanical-family-related usefulness of individual genetic markers.

No polymorphisms were detected in the standard and control adventitious shoots from 0 ppm AgNPs treatment. This underlines the mutagenic effect of silver nanoparticles, especially at higher concentrations $(0,1$, and 5 mutants were found after 5,10 , and $20 \mathrm{ppm}$ treatments, respectively). The observed mutagenic action of AgNPs is in agreement with the genotoxic effects of nanoparticles reported also in other organisms (Ghosh et al. 2019) and sheds new light on the possibility of utilizing AgNPs in the induction of somaclonal variation and plant breeding. According to An and Jin (2012), nanoparticles have a high ability to bind to nucleic acids. They can significantly change the conformation of the DNA helix, and thus, change the orientation of nitrogenous bases in the DNA 
strand. Halder et al. (2015) reported the mutagenic effect of copper nanoparticles at a concentration of 3.2-6.4 ppm in Macrotyloma uniflorum (Lam.) Verdc. (Fabaceae) with a clear phenotypic effect-altered seed coat color and number of axillary shoots produced. In the present study, only two of the novel 20 genotypes; i.e. Individuals no. 1 and no. 71 (20 ppm AgNPs); differed from the predominant standard on the phenotype level. Therefore, most of the observed mutations probably occurred in the non-coding DNA sequences. On the other hand, some plants had an altered inflorescence color or shape, despite no changes on the genomic level. This suggests the possible epigenetic action of AgNPs, causing changes in the DNA methylation and/or acetylation (Miryeganeh and Saze 2020). Similar results were reported with two cryopreservation-derived chrysanthemum cultivars, which despite no genetic variation had an altered phenotype of vegetative organs (Kulus et al. 2019). Another possibility is that the applied markers were not able to detect the mutations and other systems should also be tested, e.g. single nucleotide polymorphism (SNP), sequence-specific amplification polymorphism (SSAP) or sequence-related amplified polymorphism (SRAP) (Kulus 2018).

The frequency of mutant and mutation occurrence in the present study was $1 \%$ with $10 \mathrm{ppm}$ AgNPs treatment and 6.3 and $8.9 \%$, respectively, with $20 \mathrm{ppm}$ AgNPs treatment. In the past, X- and $\gamma$-rays (at the doses 5-25 Gy) were used in several mutation breeding programs with chrysanthemum. The frequency of mutant and mutation occurrence ranged from 2.4 to $11.6 \%$ and from 0.3 to $5.0 \%$, respectively (Zalewska et al. 2010). The current study showed that the application of AgNPs in chrysanthemum breeding can be as effective as the use of ionizing irradiation. At the same time, it is cheaper (no special apparatus needed), easier to perform, and more user-safe.

It is worth mentioning that Individual no. 71 (from 20 ppm AgNPs treatment) had a chimeric structure (sectorial or mericlinal) with light pink inflorescence, in which part of one ligulate floret was covered with a narrow strip of red color (Fig. 7). Despite the mutated sector is tiny, it can still be valuable in breeding. Somatic embryogenesis and adventitious organogenesis, due to the unicellular origin of embryos and shoots, can be successfully applied to separate the changed component and create a new attractive cultivar (Tymoszuk et al. 2014). Therefore, even such small alternations should not be neglected. Moreover, one of the most interesting and decoratively valuable mutations was observed in Individual no. 77 (20 ppm AgNPs treatment). The color of its inflorescence changed to burgundy-gold; very rare and desirable in chrysanthemum (Kulus 2017). Two of the obtained here mutants (Individual no. 1 from $10 \mathrm{ppm}$ AgNPs treatment and Individual no. 77 from $20 \mathrm{ppm}$ AgNPs treatment) received plant breeder's rights (PBR).
This highlights the utility of silver nanoparticles in chrysanthemum breeding.

\section{Conclusion}

This is the first report on the application of AgNPs in the breeding of ornamental plants at the in vitro stage. AgNPs added into the culture medium affect the regeneration and biochemical events in the plant material. Moreover, they may be a source of significant genetic variation in the in vitropropagated chrysanthemum. Silver nanoparticles are an attractive and easy-to-apply alternative to other commonly used mutagens, useful in breeding. One should keep in mind, though, that the induced variation in DNA sequence may not necessarily be manifested in the change of phenotype and vice versa. Further studies should focus on the utility of even higher AgNPs concentration (50-100 ppm) in the mutation induction.

Acknowledgements The authors wish to acknowledge Joanna Dembek and Natalia Ostojska for technical support in performing this study.

Author contributions AT conceived and designed research. AT and DK conducted the experiments, analyzed the data, and wrote the manuscript.

\section{Complaince with ethical standards}

Conflict of interest The authors declare they have no conflict of interest.

Open Access This article is licensed under a Creative Commons Attribution 4.0 International License, which permits use, sharing, adaptation, distribution and reproduction in any medium or format, as long as you give appropriate credit to the original author(s) and the source, provide a link to the Creative Commons licence, and indicate if changes were made. The images or other third party material in this article are included in the article's Creative Commons licence, unless indicated otherwise in a credit line to the material. If material is not included in the article's Creative Commons licence and your intended use is not permitted by statutory regulation or exceeds the permitted use, you will need to obtain permission directly from the copyright holder. To view a copy of this licence, visit http://creativecommons.org/licenses/by/4.0/.

\section{References}

An H, Jin B (2012) Prospects of nanoparticle-DNA binding and its implications in medical biotechnology. Biotechnol Adv 30:17211732. https://doi.org/10.1016/j.biotechadv.2012.03.007

Barbasz A, Kreczmer B, Oćwieja M (2016) Effects of exposure of callus cells of two wheat varieties to silver nanoparticles and silver salt $\left(\mathrm{AgNO}_{3}\right)$. Acta Physiol Plant 38:76. https://doi.org/10.1007/ s11738-016-2092-Z

Barbasz A, Kreczmer B, Oćwieja M (2018) How the surface properties affect nanocytotoxicity of silver? Study of the three types of 
nanosilver on two wheat varieties. Acta Physiol Plant 40:31. https ://doi.org/10.1007/s11738-018-2613-z

Barrena R, Casals E, Colón J, Font X, Sánchez A, Puntes V (2009) Evaluation of the ecotoxicity of model nanoparticles. Chemosphere 75:850-857. https://doi.org/10.1016/j.chemospher e.2009.01.078

Chahardoli A, Karimi N, Ma X, Qalekhani F (2020) Effects of engineered aluminium and nickel oxide nanoparticles on the growth and antioxidant defense systems of Nigella arvensis L. Sci Rep 10:3847. https://doi.org/10.1038/s41598-020-60841-6

Cvjetko P, Zovko M, Peharec Štefanić P, Biba R, Tkalec M, Domijan AM, Vinković Vrček I, Letofsky-Papst I, Šikić S, Balen B (2018) Phytotoxic effects of silver nanoparticles in tobacco plants. Environ Sci Pollut Res 25:5590-5602. https://doi.org/10.1007/s1135 6-017-0928-8

Dewez D, Golsev V, Kalaji HM, Oukarroum A (2018) Inhibitory effects of silver nanoparticles on photosystem II performance in Lemna gibba probed by chlorophyll fluorescence. Curr Plant Biol 16:15-21. https://doi.org/10.1016/j.cpb.2018.11.006

Dumont S, Rivoal J (2019) Consequences of oxidative stress on plant glycolytic and respiratory metabolism. Front Plant Sci 10:166. https://doi.org/10.3389/fpls.2019.00166

Dietz KJ, Herth S (2011) Plant nanotoxicology. Trends Plant Sci 16(1):582-589. https://doi.org/10.1016/j.tplants.2011.08.003

Domeradzka-Gajda K, Nocuń M, Roszak J, Janasik B, Quarles CD Jr, Wąsowicz W, Grobelny J, Tomaszewska E, Celichowski G, Ranoszek-Soliwoda K, Cieślak M, Puchowicz D, Gonzalez JJ, Russo RE, Stępnik M (2017) A study on the in vitro percutaneous absorption of silver nanoparticles in combination with aluminum chloride, methyl paraben or di-n-butyl phthalate. Toxicol Lett 272:38-48. https://doi.org/10.1016/j.toxlet.2017.03.006

Faizan M, Faraz A, Yusuf Y, Khan ST, Hayat S (2018) Zinc oxide nanoparticle-mediated changes in photosynthetic efficiency and antioxidant system of tomato plants. Photosynthetica 56(2):678-686. https://doi.org/10.1007/s11099-017-0717-0

Fayez KA, El-Deeb BA, Mostafa NY (2017) Toxicity of biosynthetic silver nanoparticles on the growth, cell ultrastructure and physiological activities of barley plant. Acta Physiol Plant 39:155. https://doi.org/10.1007/s11738-017-2452-3

Fernández ME, Figueiras AM, Benito C (2002) The use of ISSR and RAPD markers for detecting DNA polymorphism, genotype identification and genetic diversity among barley cultivars with known origin. Theor Appl Genet 104(5):845-851. https://doi. org/10.1007/s00122-001-0848-2

Ghosh M, Ghosh I, Godderis L, Hoet P, Mukherjee A (2019) Genotoxicity of engineered nanoparticles in higher plants. Mut Res Genet Toxicol Environ Mut 842:132-145. https://doi. org/10.1016/j.mrgentox.2019.01.002

Ghosh M, Jana A, Sinha S, Jothiramajayam M, Nag A, Chakraborty A, Mukherjee A, Mukherjee A (2016) Effects of $\mathrm{ZnO}$ nanoparticles in plants: cytotoxicity, genotoxicity, deregulation of antioxidant defenses, and cell-cycle arrest. Mutat Res Genet Toxicol Environ Mutagen 807:25-32. https://doi.org/10.1016/j. mrgentox.2016.07.006

Halder S, Mandal A, Das D, Chattopadhyay AP, Datta AK (2015) Copper nanoparticle induced macromutation in Macrotyloma uniflorum (Lam.) Verdc. (Leguminosae): a pioneer report. Genet Resour Crop Evol 62:165-175. https://doi.org/10.1508/cytol ogia.82.267

Harborne JB (1967) Comparative biochemistry of the flavonoids. Phytochemistry 6(11):1569-1573. https://doi.org/10.1016/S0031 -9422(00)82952-0

Hou J, Wu Y, Li X, Wei B, Li S, Wang X (2018) Toxic effects of different types of zinc oxide nanoparticles on algae, plants, invertebrates, vertebrates and microorganism. Chemosphere 193:852860. https://doi.org/10.1016/j.chemosphere.2017.11.077
Jaleel CA, Manivannan P, Wahid A, Farooq M (2009) Drought stress in plants: a review on morphological characteristics and pigments composition. Int J Agric Biol 11(1):100-105

Khot LR, Sankaran S, Maja JM, Ehsanie R, Schuster EW (2012) Application of nanomaterials in agricultural production and crop protection: a review. Crop Prot 35:64-70. https://doi.org/10.1016/j. cropro.2012.01.007

Krishnaraj C, Jagan EG, Ramachandran R, Abirami SM, Mohan N, Kalaichelvan PT (2012) Effect of biologically synthesized silver nanoparticles on Bacopa monnieri (Linn.) Wettst. plant growth metabolism. Process Biochem 47:651-658. https://doi. org/10.1016/j.procbio.2012.01.006

Kulus D (2017) Selected aspects of biology, breeding and reproduction of chrysanthemum. ZPPNR 588:47-61. https://doi.org/10.22630 IZPPNR.2017.588.5

Kulus D (2018) Genetic resources and selected conservation methods of tomato. J Appl Bot Food Qual 91:135-144. https://doi. org/10.5073/JABFQ.2018.091.00X

Kulus D, Rewers M, Serocka M, Mikuła A (2019) Cryopreservation by encapsulation-dehydration affects the vegetative growth of chrysanthemum but does not disturb its chimeric structure. Plant Cell Tissue Org Cult 138(1):153-166. https://doi.org/10.1007/s1124 0-019-01614-6

Kumari M, Khan SS, Pakrashi S, Mukherjee A, Chandrasekaran N (2011) Cytogenetic and genotoxic effect of zinc oxide nanoparticles on root cells of Allium cepa. J Hazard Mater 90:613-621. https://doi.org/10.1016/j.jhazmat.2011.03.095

Lema-Rumińska J, Kulus D, Tymoszuk A, Varejão JMTB, Bahcevandziev K (2019) Profile of secondary metabolites and genetic stability analysis in new lines of Echinacea purpurea (L.) Moench micropropagated via somatic embryogenesis. Ind Crops Prod 142:111851. https://doi.org/10.1016/j.indcrop.2019.111851

Lichtenthaler HK (1987) Chlorophylls and carotenoids: pigments of photosynthetic biomembranes. Method Enzymol 148:350-382. https://doi.org/10.1016/0076-6879(87)48036-1

Mandeh M, Omidi M, Rahaie M (2012) In vitro influences of $\mathrm{TiO}_{2}$ nanoparticles on barley (Hordeum vulgare L.) tissue culture. Biol Trace Element Res 150(1-3):376-380. https://doi.org/10.1007/ s12011-012-9480-z

Mazumdar H (2014) The impact of silver nanoparticles on plant biomass and chlorophyll content. Int J Eng Sci 4(7):12-20

Mehrian SK, De Lima R (2016) Nanoparticles cyto and genotoxicity in plants: mechanisms and abnormalities. Environ Nanotechnol Monit Manag 6:184-193. https://doi.org/10.1016/j. enmm.2016.08.003

Miler N, Jędrzejczyk I (2018) Chrysanthemum plants regenerated from ovaries: a study on genetic and phenotypic variation. Turk J Bot 42(3):289-297. https://doi.org/10.3906/bot-1707-19

Minano HS, Gonzales-Benito ME, Martin C (2009) Molecular characterization and analysis of somaclonal variation in chrysanthemum cultivars using RAPD markers. Sci Hortic 122:238-243. https:// doi.org/10.1016/j.scienta.2009.05.001

Miryeganeh M, Saze H (2020) Epigenetic inheritance and plant evolution. Popul Ecol 62(1):17-27. https://doi. org/10.1002/1438-390X.12018

Mirzajani F, Askari H, Hamzelou S, Ghassempour A (2013) Effect of silver nanoparticles on Oryza sativa L. and its rhizosphere bacteria. Ecotoxicol Environ Saf 88:48-54. https://doi.org/10.1016/j. ecoenv.2012.10.018

Mukhejee AK, Dey A, Acharya L, Palai SK, Panda PC (2013) Studies on genetic diversity in elite varietes of Chrysanthemum using RAPD, and ISSR markers. Indian J Biotechnol 12:161-169

Murashige T, Skoog F (1962) A revised medium for rapid growth and bio assays with tobacco tissue cultures. Physiol Plant 15:473-497. https://doi.org/10.1111/j.1399-3054.1962.tb08052.x 
Nanjundiah V (1993) Why are most mutations recessive? J Genet 72:85. https://doi.org/10.1007/BF02927924

Nei M, Li WS (1979) Mathematical model for studying genetic variation in terms of restriction nucleases. Proc Natl Acad Sci 76(10):5269-5273. https://doi.org/10.1073/pnas.76.10.5269

Noctor G, Lelarge-Trouverie C, Mhamdi A (2015) The metabolomics of oxidative stress. Phytochemistry 112:33-53. https://doi. org/10.1016/j.phytochem.2014.09.002

Panda KK, Achary VMM, Krishnaveni R, Padhi BK, Sarangi SN, Sahu SN, Panda BB (2011) In vitro biosynthesis and genotoxicity bioassay of silver nanopaticles using plants. Toxicol In Vitro 25:1097-1105. https://doi.org/10.1016/j.tiv.2011.03.008

Patllola AK, Berry A, May L, Tchounwou PB (2012) Genotoxicity of silver nanoparticles in Vicia faba: A pilot study on the environmental monitoring of nanoparticles. Int J Environ Res Public Health 9:1649-1662. https://doi.org/10.3390/ijerph9051649

Peakall R, Smouse PE (2012) GenAlEx 6.5: genetic analysis in Excel. Population genetic software for teaching and research-an update. Bioinformatics 28(19):2537-2539. https://doi.org/10.1093/bioin formatics/bts460

Pudlarz A, Czechowska E, Ranoszek-Soliwoda K, Tomaszewska E, Celichowski G, Grobelny J, Szemraj J (2018) Immobilization of recombinant human catalase on gold and silver nanoparticles. Appl Biochem Biotechnol 185(3):717-735. https://doi. org/10.1007/s12010-017-2682-2

Qian W, Ge S, Hong DY (2001) Genetic variation within and among populations of a wild rice Oryza granulata from China detected by RAPD and ISSR markers. Theor Appl Genet 102:440-449. https://doi.org/10.1007/s001220051665

Reed RB, Lander DA, Higgins ChP, Westerhoff P, Ranville JF (2012) Solubility of nano-zinc oxide in environmentally and biologically important matrices. Environ Toxicol Chem 31(1):93-99. https:// doi.org/10.1002/etc.708

RHSCC (1966) The Royal Horticultural Society Colour Chart. RHSCC, London

Sabir S, Arshad M, Chaudhari SK (2014) Zinc oxide nanoparticles for revolutionizing agriculture: synthesis and applications. Sci World J 2014:8. https://doi.org/10.1155/2014/925494

Salama HMH (2012) Effects of silver nanoparticles in some crop plants, common bean (Phaseolus vulgaris L.) and corn (Zea mays L.). Int Res J Biotechnol 3(10):190-197

Singh A, Singh NB, Afzal S, Singh T, Hussain I (2018) Zinc oxide nanoparticles: a review of their biological synthesis, antimicrobial activity, uptake, translocation and biotransformation in plants. J Mater Sci 53:185-201. https://doi.org/10.1007/s1085 3-017-1544-1
Syu YY, Hung JH, Chen JC, Chuang HW (2014) Impacts of size and shape of silver nanoparticles on Arabidopsis plant growth and gene expression. Plant Physiol Biochem 83:57-64. https://doi. org/10.1016/j.plaphy.2014.07.010

Teixeira da Silva JA, Kulus D (2014) Chrysanthemum biotechnology: discoveries from the recent literature. Folia Hortic 26(2):67-77. https://doi.org/10.2478/fhort-2014-0007

Tymoszuk A, Miler N (2019) Silver and gold nanoparticles impact on in vitro adventitious organogenesis in chrysanthemum, gerbera and Cape Primrose. Sci Hortic 257:108766. https://doi. org/10.1016/j.scienta.2019.108766

Tymoszuk A, Zalewska M, Lema-Rumińska J (2014) Regeneration of somatic embryos from in vitro isolated ligulate florets of chrysanthemum. Acta Sci Pol Hort Cult 13:4-13

Van Assche F, Clijsters H (1990) Effects of metals on enzyme activity in plants. Plant Cell Environ 13:195-206. https://doi. org/10.1111/j.1365-3040.1990.tb01304.x

Vannini C, Domingo G, Onelli E, De Mattia F, Bruni I, Marsoni M, Bracale M (2014) Phytotoxic and genotoxic effects of silver nanoparticles exposure on germinating wheat seedlings. J Plant Physiol 171:1142-1148. https://doi.org/10.1016/j.jplph.2014.05.002

Waterhouse AL (2001) Determination of total phenolics. In: Wrolstad RE (ed) Current protocols in food analytical chemistry. Wiley, New York, pp I111-I118

Yan A, Chen Z (2019) Impacts of silver nanoparticles on plants: a focus on the phytotoxicity and underlying mechanism. Int J Mol Sci 20(5):1003. https://doi.org/10.3390/ijms20051003

Yasur J, Rani P (2013) Environmental effects of nanosilver: impact on castor seed germination, seedling growth, and plant physiology. Environ Sci Pollut Res 20:8636-8648. https://doi.org/10.1007/ s11356-013-1798-3

Zalewska M, Miler N, Tymoszuk A, Drzewiecka B, Winiecki J (2010) Results on mutation breeding activity in Chrysanthemum $\times$ grandiflorum (Ramat.) Kitam. in Poland. Electr J Pol Agric Univ 13(4):27

Zalewska M, Tymoszuk A, Miler N (2011) New chrysanthemum cultivars as a result of in vitro mutagenesis with the application of different explant types. Acta Sci Pol Hort Cult 10(2):109-123

Publisher's Note Springer Nature remains neutral with regard to jurisdictional claims in published maps and institutional affiliations. 